\title{
Article \\ Classification Ensembles for Beach Cast and Drifting Vegetation Mapping with Sentinel-2 and PlanetScope
}

\author{
Florian Uhl ${ }^{1, *}$, Trine Græsdal Rasmussen ${ }^{2}$ and Natascha Oppelt ${ }^{1}$ (D) \\ 1 Department of Geography, Kiel University, Ludewig-Meyn-Str. 8, 24118 Kiel, Germany; \\ oppelt@geographie.uni-kiel.de \\ 2 Department of Marine Ecology, GEOMAR Helmholtz Centre for Ocean Research Kiel, Hohenbergstraße 2, \\ 24105 Kiel, Germany; tgraesdal-rasmussen@geomar.de \\ * Correspondence: uhl@geographie.uni-kiel.de; Tel.: +49-431-880-5583
}

check for

updates

Citation: Uhl, F.; Græsdal

Rasmussen, T.; Oppelt, N.

Classification Ensembles for Beach

Cast and Drifting Vegetation

Mapping with Sentinel-2 and

PlanetScope. Geosciences 2022, 12, 15.

https://doi.org/10.3390/

geosciences 12010015

Academic Editors: Vincent Lecours

and Jesus Martinez-Frias

Received: 25 October 2021

Accepted: 25 December 2021

Published: 29 December 2021

Publisher's Note: MDPI stays neutral with regard to jurisdictional claims in published maps and institutional affiliations.

Copyright: (C) 2021 by the authors. Licensee MDPI, Basel, Switzerland. This article is an open access article distributed under the terms and conditions of the Creative Commons Attribution (CC BY) license (https:// creativecommons.org/licenses/by/ $4.0 /)$.

\begin{abstract}
Along the Baltic coastline of Germany, drifting vegetation and beach cast create overlays at the otherwise sandy or stony beaches. These overlays influence the morphodynamics and structures of the beaches. To better understand the influence of these patchy habitats on coastal environments, regular monitoring is necessary. Most studies, however, have been conducted on spatially larger and temporally more stable occurrences of aquatic vegetation such as floating fields of Sargassum. Nevertheless, drifting vegetation and beach cast pose a particular challenge, as they exhibit high temporal dynamics and sometimes small spatial extent. Regular surveys and mappings are the traditional methods to record their habitats, but they are time-consuming and cost-intensive. Spaceborne remote sensing can provide frequent recordings of the coastal zone at lower cost. Our study therefore aims at the monitoring of drifting vegetation and beach cast on spatial scales between 3 and $10 \mathrm{~m}$. We developed an automated coastline masking algorithm and tested six supervised classification methods and various classification ensembles for their suitability to detect small-scale assemblages of drifting vegetation and beach cast in a study area at the coastline of the Western Baltic Sea using multispectral data of the sensors Sentinel-2 MSI and PlanetScope. The shoreline masking algorithm shows high accuracies in masking the land area while preserving the sand-covered shoreline. We could achieve best classification results using PlanetScope data with an ensemble of a random forest classifier, cart classifier, support vector machine classifier, naïve bayes classifier and stochastic gradient boosting classifier. This ensemble accomplished a combined f1-score of 0.95 . The accuracy of the Sentinel-2 classifications was lower but still achieved a combined f1-score of 0.86 for the same ensemble. The results of this study can be considered as a starting point for the development of time series analysis of the vegetation dynamics along Baltic beaches.
\end{abstract}

Keywords: Sentinel-2; PlanetScope; classification; ensembles; seagrass; macroalgae; shoreline; sandy beaches

\section{Introduction}

Sandy beaches dominate more than one-third of the world's coastline [1] and provide numerous ecosystem services such as storage and transport of sediment, the breakdown of organic materials and pollutants or the maintenance of biodiversity and genetic resources [2]. Nevertheless, many beaches show low primary production rates, a generally limited food supply or little shelter from predators [3]. Coastal macroalgal habitats or seagrass meadows can deliver a substantial input of organic material to the beaches in form of dissolved organic matter or particulate organic matter [3,4]. Furthermore, detached and drifting vegetation can influence the water circulation and the morphology of a coastal area by forming wrack banks on the beach or drifting patches in the water, therefore delivering shelter for microorganisms [5]. Beach cast has important ecological functions such as providing habitat, shelter or food. It stimulates the microbial food web [6]; moreover, studies 
demonstrated a positive effect of decomposing beach cast on the growth of mussels [7] or mysids [8]. Consequently, a comprehensive mapping of aquatic vegetation on and along beaches is crucial for marine protected area planning, sustainable beach cast cleaning and ecological research.

Drifting vegetation and beach cast are therefore particularly important for sandy beach ecology. Drifting vegetation is an aggregation of detached macroalgae (sometimes mixed with seagrass) floating close to the water surface or near the bottom of the coastal sea. While floating, the species are alive, actively photosynthesizing and thus break down slowly [9]. They form loose patches in the surf zone providing feeding habitat, nursery area or shelter for fish and small, weak-swimming detritivores/omnivores [10,11]. Beach cast, also called wrack band, beach strand, beach wreck, banquettes or stormcast is unattached macrovegetation that is washed ashore by waves or tides and accumulated on the beach. The species composition of the washed-up vegetation reflects the species assemblage in the nearshore habitats. Consequently, beach cast provides information on drifting and sessile aquatic habitats that are difficult to access or highly dynamic over time. Therefore, the sampling of beach cast is an alternative for investigating the species composition of macrovegetation in near-coastal habitats [12].

In the last years, remote sensing techniques have become an extensively used method for macrovegetation mapping $[13,14]$ providing good estimates of aquatic vegetation coverage $[15,16]$. Moreover, remote sensing can provide long-term data to better understand ecosystem structures and changes [17]. Especially spaceborne datasets are an important time-saving supplement to traditional field surveys and offer lower costs per square kilometer [14]. Various techniques have been applied for vegetation mapping in aquatic environments, for example thresholding, spectral indices, regression analysis, visual interpretation or unsupervised classification. However, supervised classifiers remain the most common approaches, such as the maximum likelihood classification, the spectral angle mapper, the support vector machine and, in recent years, the random forest classification. In typical study arrangements, the authors apply two to three approaches independent of each other. Afterwards, they compare the classification results to determine the best approach [18-22]. Studies focusing on terrestrial surfaces, however, indicate that an ensemble of classifiers, i.e., the combination of multiple classifiers to a joint model, may be more accurate than any of the single classifiers [23]. Nevertheless, there is no study addressing the use of ensembles for beach cast and drifting vegetation assessment.

The satellite missions Sentinel-2 (S-2, since 2015) and PlanetScope (PS, since 2016) deliver satellite data with a high temporal resolution (S-2: 5 days; PS: almost daily) which is of special importance for monitoring dynamic coastal regions. Existing studies show the suitability of both sensors for the detection of macrovegetation, although there are significantly more studies for S-2 [18-22]. These studies, however, focused on sessile vegetation or large drifting macroalgal assemblages. Analyses of small agglomerations directly on the shoreline or at the sandy beach (beach cast) are missing.

A crucial step for vegetation analysis along the coastline is the extraction of the shoreline in the remote sensing data, whereas a wide range of published shoreline extraction algorithms exists. Nevertheless, they already differ in the definition of the term "shoreline" [24]. An established and often cited definition is, that the shoreline coincides with the physical interface of land and water [25]. This definition, however, does not account for temporal changes of the shoreline due to tides, waves, or a changing sea level, which may alter the position of the shoreline periodically or by several meters within a few years [26]. A spatially more flexible definition that considers these variations would be more appropriate for studies analyzing the zone of beach and water together. Accordingly, Toure et al. [24] defined the shoreline by the upper and lower limits of the water movement. Thus, this expanded definition of shoreline also includes the distribution border of beach cast, the winter berm. Consequently, a shoreline delineation algorithm for beach cast studies must meet this definition. Existing approaches include multi-threshold based morphological methods to extract the shoreline from optical remote sensed images [27]. Aedla et al. [28] 
used adaptive thresholding to separate the image into water and non-water areas. Further techniques for separating land and water are pixel-based spectral classifications [29] or object-oriented fuzzy methods [30]. In addition to these separation techniques, several scientists expanded the data feature space by including spectral indices such as the Floating Algae Index (FAI) [31] or the Normalized Difference Water Index (NDWI) [32]. Although a variety of algorithms exists [24], none of the concepts addresses multi-temporal approaches, where scenes of several years may be piled to create an average beach-area including sand covered beach areas together with coastal waters. Toure et al. [24] state, that future work should be directed for a complete automation of shoreline separation algorithms. In this paper, we therefore included multiple scenes to calculate the average shoreline, which reduces or even removes the influences of temporally high-frequent effects. In addition, this step eliminates the need to adjust thresholds based on current conditions for the shoreline delineation. As a result, a multi-temporal shoreline processor operates almost automatically.

The automated shoreline detection approach is a prerequisite for addressing our main objective, i.e., to test the suitability of S-2 and PS for mapping drifting vegetation in shallow waters and beach cast on sandy beaches of the western Baltic Sea. We focused on S-2 and PS since both sensors are easily available for scientific users and public authorities. We applied and combined different classification approaches to S-2 and PS data to determine which classification or classification ensemble delivers the best mapping result for each of the two sensors.

\section{Materials and Methods}

\subsection{Study Area}

We conducted this study at the Baltic Sea beaches of the Probstei coast (Figure 1). The Probstei coast is an approximately $20 \mathrm{~km}$ long coastal area in the federal state of Schleswig-Holstein, Germany. We selected a subsection of the Probstei coast including the beaches of Mönkeberg, Heidkate, Brasilien, Kalifornien and Stakendorfer Strand. This section is a northward dipping open Pleistocene strip dissected by several channels up to $25 \mathrm{~m}$ depth [33]. This shallow coastal area is exposed to waves from west-northwest to northeast [34]. Changing winds and varying water level make this coastal lowland with its extensive sandy beaches prone to sea level rise and extreme storm surges [35]. Therefore, coastal protection structures characterize this area, which include a $14.3 \mathrm{~km}$ long dike and 48 large stone groynes made of erratic boulders. Every $200 \mathrm{~m}$, one of these T-shaped groynes extends up to $100 \mathrm{~m}$ into the Baltic Sea [33]. The Probstei coast shows a typical seasonal mobility of sediment with the lowest mobility occurring during the summer months (May to August) and the maximum during the winter period (November to February). The nearshore bar system includes up to four sand bars and extends seawards up to $700 \mathrm{~m}$ [34].

The aquatic vegetation in the study area consists of macroalgal species and seagrass. The diversity of macroalgae species is relatively low due to the reduced salinity and lack of hard substrata [36]. In our study area, we can distinguish four main groups of aquatic vegetation with the corresponding dominant species (Figure 2):

1. Submerged seagrass beds on the sandy substrate offshore, dominated by Zostera marina.

2. Brown algae agglomerations on the groynes, dominated by Fucus vesiculosus.

3. Drifting patches of detached seagrass fragments and various macroalgae at and close to the shoreline such as: Ceramium secundatum, Ceramium tenuicorne, Vertebrata fucoides, Cladophora glomerata, Ulva sp., Phycodrys rubens.

4. Beach cast over the sandy beach consisting of Zostera marina and the macroalgae of the drift compositions. Due to the faster decomposition of macroalgae, older deposits are dominated by fractions of seagrass. 


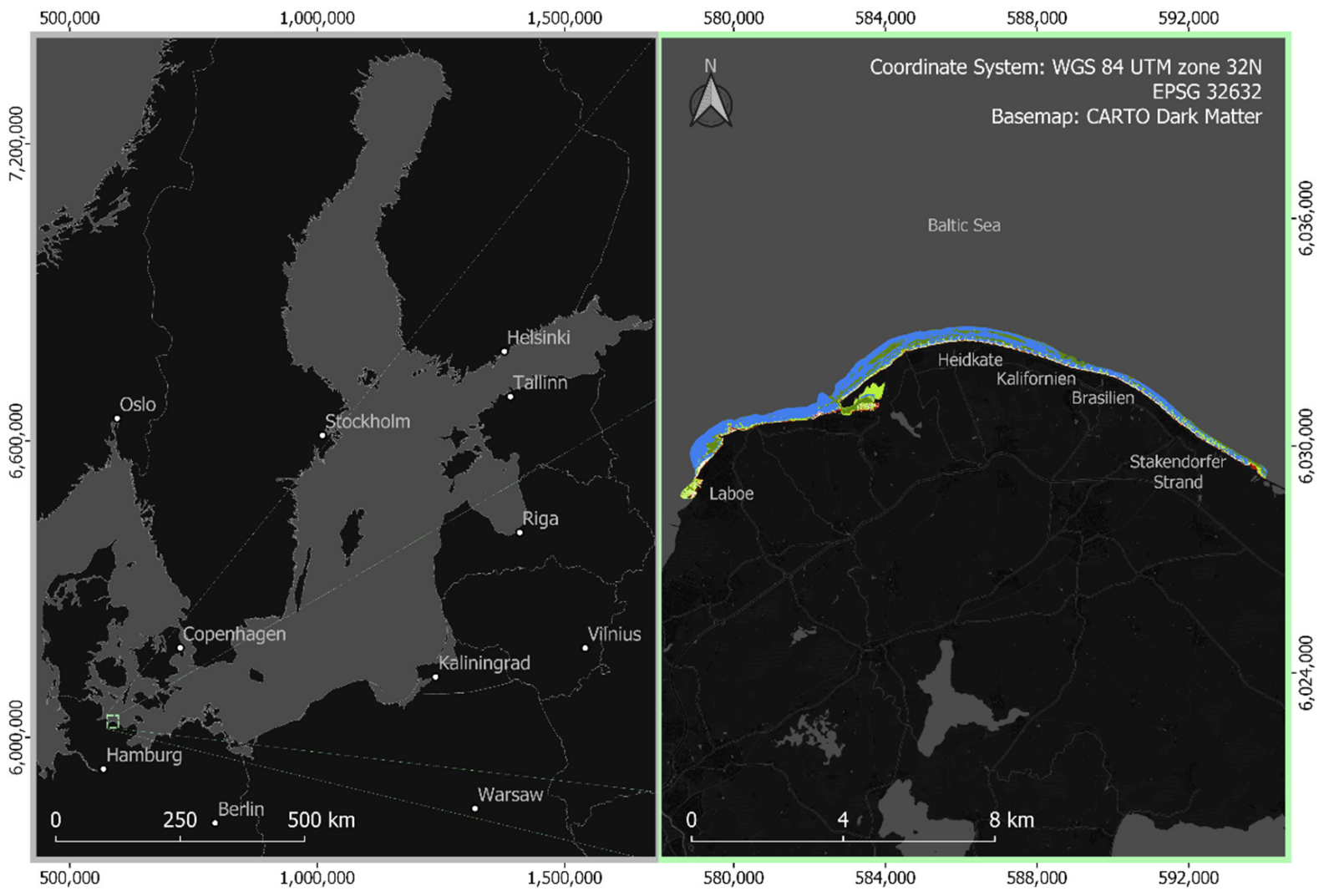

Figure 1. Location of the study area.

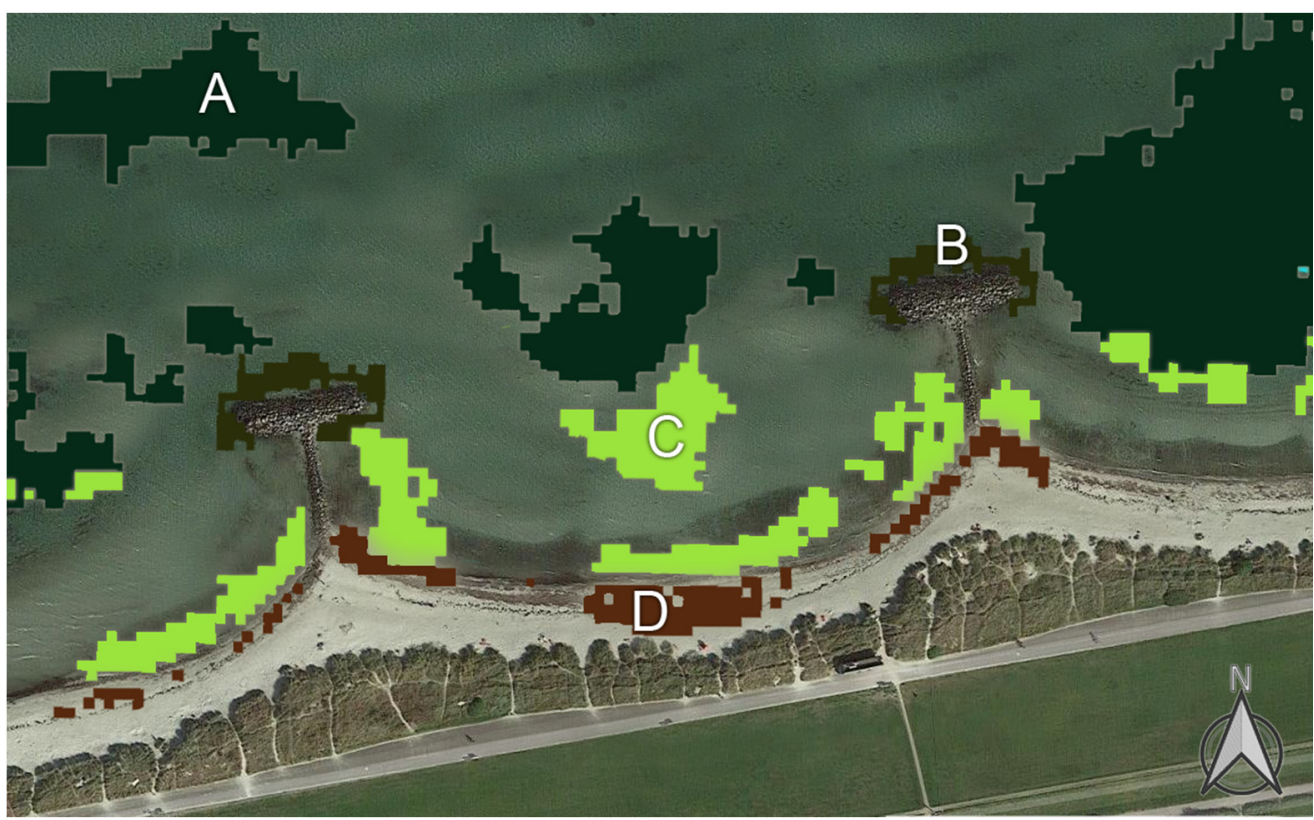

Figure 2. Schematic illustration of the typical zonation of the four dominant aquatic vegetation groups modified from PS data. (A-dark green) submerged seagrass, (B-moss green) fixed brown algae, (C-light green) drifting mix of seagrass and macroalgae and ( $\mathrm{D}$-brown) beach cast mixed of seagrass and macroalgae. Background map data: modified Google satellite.

\subsection{Field Mapping}

We conducted field surveys during summer 2020 at three sections of the Probstei coastline: Mönkeberg, Brasilien and Stakendorfer Strand. Of particular interest for this 
study is a beach cast mapping from 21 September, as it was held out at Schönberger Strand close to the date of the satellite data acquisition between 14:00 and 16:00 local time. The weather conditions were calm and sunny with few scattered cirrus clouds. The data was always collected by foot and with waders in the water. The distance from the shore, where the accumulations could be mapped, was therefore determined by the water depth that could be reached with waders. We recorded the extent and the composition of the vegetation assemblages at the sandy beach and in the shallow water. Using a Garmin $64 \mathrm{~s}$ GPS in the tracking mode enabled us to record the shape and location of the assemblages with an accuracy of $3.65 \mathrm{~m} \mathrm{[36].} \mathrm{Through} \mathrm{this} \mathrm{procedure,} \mathrm{we} \mathrm{mapped} \mathrm{the} \mathrm{coverage} \mathrm{of}$ 53 patches, which we digitized as polygon shapefiles. Furthermore, the mapping team recorded the species composition at each of the patches. We reduced this dataset to create training and validation data for the four dominant aquatic vegetation groups without considering the species composition (Figure 2).

\subsection{Satellite Data}

In this study, we used two satellite scenes from two different multispectral sensors, i.e., S-2 MSI and PS. Since drifting algae can rapidly change their position/extend based on wind direction, currents and waves, we decided to consider only the satellite data acquired nearest to the field mapping.

\subsubsection{Sentinel-2 MSI}

S-2 (A and B) are two polar-orbiting, high-resolution, multi-spectral imaging satellites from the European Space Agency (ESA). They carry optical sensors sampling 13 spectral bands between 458 and $2280 \mathrm{~nm}$. The spatial resolution of the bands varies between $10 \mathrm{~m}$ to $60 \mathrm{~m}$. The twin satellites provide mapping capabilities comparable to SPOT and Landsat data with a revisit time of 5 days at the equator $[37,38]$.

We used a S-2 Level-2A data set available in the Google Earth Engine (GEE) [39]. Google downloads the data directly from Sci-Hub [39]. The Level-2A product provides Bottom of Atmosphere (BOA) reflectances generated with the Sen2Cor processor and encoded in a 12 bit SAFE format [40]. The scene used in this study was acquired from S-2A on 14 September 2020.

\subsubsection{PlanetScope}

The small PS CubeSat Satellites are operated by Planet Labs, Inc. Approximately 130 PS satellites cover the entire land surface of the Earth every day. The spectral resolution offers four bands between 455 and $860 \mathrm{~nm}$. The ground sampling distance is approximately $3.7 \mathrm{~m} \times 3.7 \mathrm{~m}$ but the data are distributed resampled to $3 \mathrm{~m} \times 3 \mathrm{~m}$ in a 16-bit GeoTIFF format. We used the PS 3B Analytic Ortho Scene Product with an accurate geolocation, cartographic projection and data processed to surface reflectance. The atmospheric correction is implemented using LUTs generated by the $6 \mathrm{~S}$ radiative transfer model [41] and near-real-time MODIS aerosol optical depth (AOD) data [42]. This product type is specified as optimal for land cover classifications [43]. The scene used in this study was acquired on 21 September 2020.

\subsection{Advanced Shoreline Masking}

In the study area, the four vegetation groups are distributed both in the water and on the sandy beach. We therefore developed a processing chain to separate the terrestrial areas while retaining the dry beach for further analysis. This processing step is called advanced shoreline masking (ASM). To create this "land-water mask", we used a time series of S-2 scenes between 2016 and 2020 with a scene cloud cover of less than $20 \%$. For our study area, the resulting stack of scenes comprised 94 images. Then we removed clouds from the scenes by evaluating the SCL (Scene Classification Map) band and the QA60 band of the Level-2A product. From the SCL band we filtered the classes cloud shadows (3), cloud 
medium (8), cloud high (9), cirrus (11) and snow /ice (11). From the QA60 band, pixels with values 10 (clouds present) and 11 (cirrus present) were removed.

Afterwards, we calculated the median reflectance for each pixel considering all masked scenes. The result was a single median reflectance scene with a median determined without the influence of clouds, cloud shadows or snow. We then used this cloud- and cloud shadow-masked median product to calculate the Modified Normalized Difference Water Index at $10 \mathrm{~m}$ spatial resolution (MNDWI $10 \mathrm{~m}$ ) [44]. The MNDWI $10 \mathrm{~m}$ extracts water pixels more accurately than a standard Modified Normalized Difference Water (MNDWI) index with $20 \mathrm{~m}$ spatial resolution [44]. The MNDWI $10 \mathrm{~m}$ is calculated using a sharpened band 11 (SWIR) and band 3 (Green) combination. The sharpening of band 11 consists of three steps: First, band 8 is filtered with a high pass filtered (HPF) to emphasize the high frequencies in the band [45]. Then, band 11 and the filtered band 8 are added. Finally, the sum of the bands is divided by two to determine the average reflection. Contrary to the results from Du et al. [44], HPF data showed best results for land-water masking in this study. As high pass filter, we used a $3 \times 3$ box filter with a kernel center of 1.6 and a surrounding weight of 0.0625 based on the approach introduced by Chavez Jr. et al. [46]. We sharpened band 11 by using spatial and spectral information from the $10 \mathrm{~m}$ band 8 . Band 11 has a spatial resolution of $20 \mathrm{~m}$ and band 8 has a spatial resolution of $10 \mathrm{~m}$. By sharpening band 11 with band 8 , we create a new sharpened band 11 with a spatial resolution of $10 \mathrm{~m}$ and a combined spectral information from band 11 with band 8 . This procedure is similar to the established pansharpening. However, since S-2 has no PAN band, the finer spatial information is obtained from band 8 instead of a PAN band. Then we calculated the difference between the Normalized Difference Vegetation Index (NDVI) and the MNDWI to extract water pixels as introduced by Zhou et al. [47], but using the MNDWI $10 \mathrm{~m}$ instead of the MNDWI. Finally, we extracted the dry beach together with all water pixels by creating a mask that retains all pixels with an NDVI-MNDVI $10 \mathrm{~m}$ less than 0.5 (Figure 3).

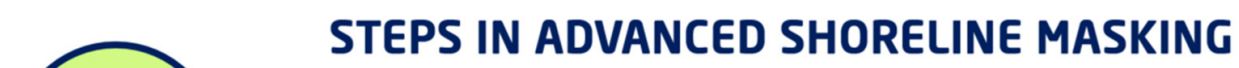

NDVI-MNDWI-combined index less than 0.5

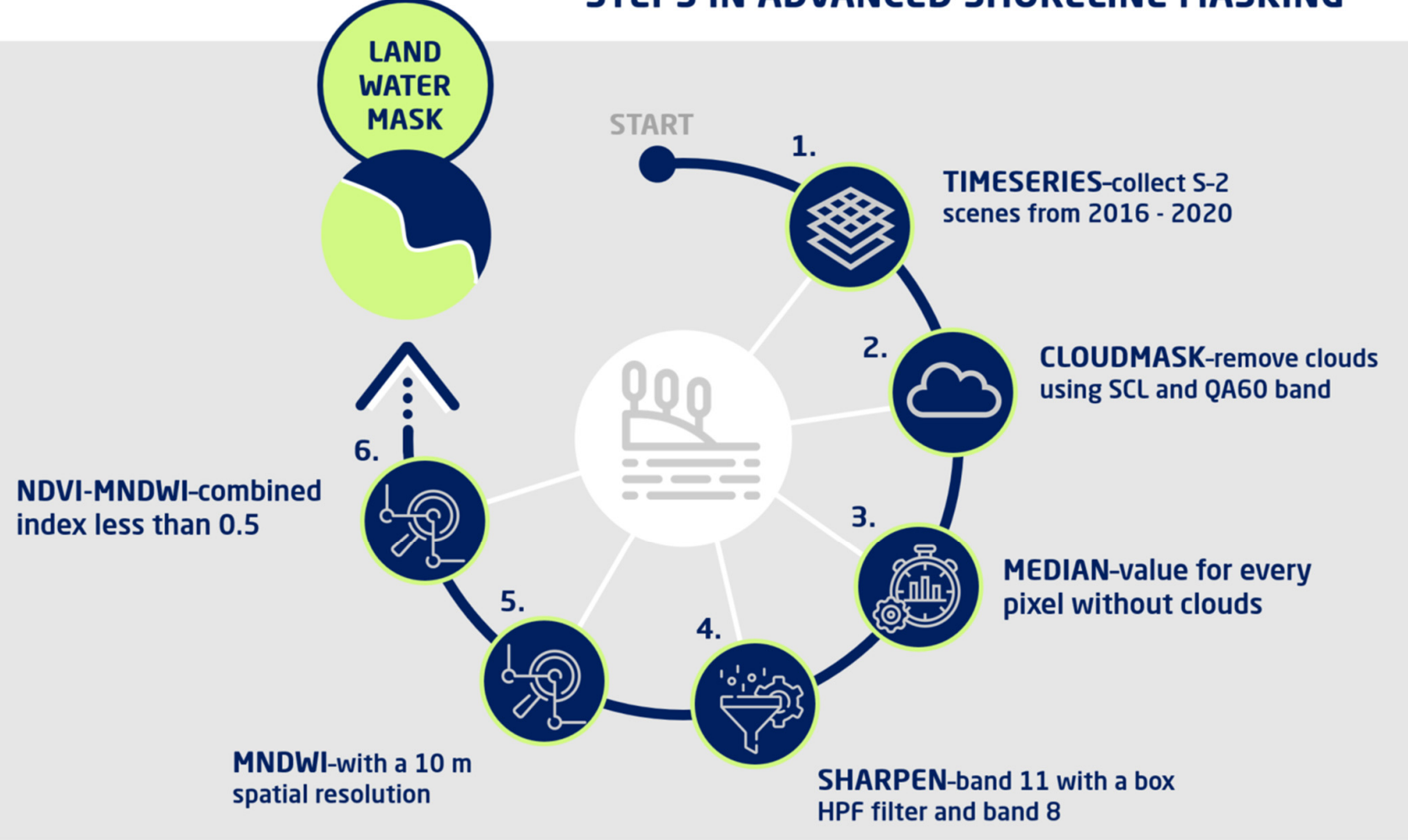

\section{STEPS IN ADVANCED SHORELINE MASKING}

Figure 3. The six steps of the land-water mask creation with preservation of the sandy beach area. 


\subsection{Classifier Ensemble}

Ensemble data mining methods, also known as classifier ensembles, are mainly used for land cover classifications to improve the classification result $[48,49]$. We are unaware of studies that examine the suitability of classification ensembles for detecting beach cast and drifting vegetation. We combined up to six established supervised classification methods to form an ensemble. Investigating whether the combination of multiple classification methods adds value to the detection of these two vegetation assemblages. At first, we examined the performance of each method individually. Subsequently, we combined the results of the individual classifiers to form an ensemble. In this context, we also tested, which set of classifiers performs best as an ensemble by iteratively combining different classifiers. The results of the individual classifications are combined by determining the most frequently classified class for each pixel. We integrated this approach, which is also called majority vote, where all classifiers have the same weight on the resulting classification [50]. Consequently, the first tuning parameters were the number and the combination of the classifiers that form the ensemble-beginning with all possible combinations of two classifiers up to the combination of all six classifiers in one ensemble. The second set of tuning parameters was the number and selection of bands used for the classification. We tested different band combinations for both sensors. In addition, we added two other variables as additional bands, the FAI [31] and the NDVI (Figure 4).

\section{STEPS IN ENSEMBLE TRAINING}

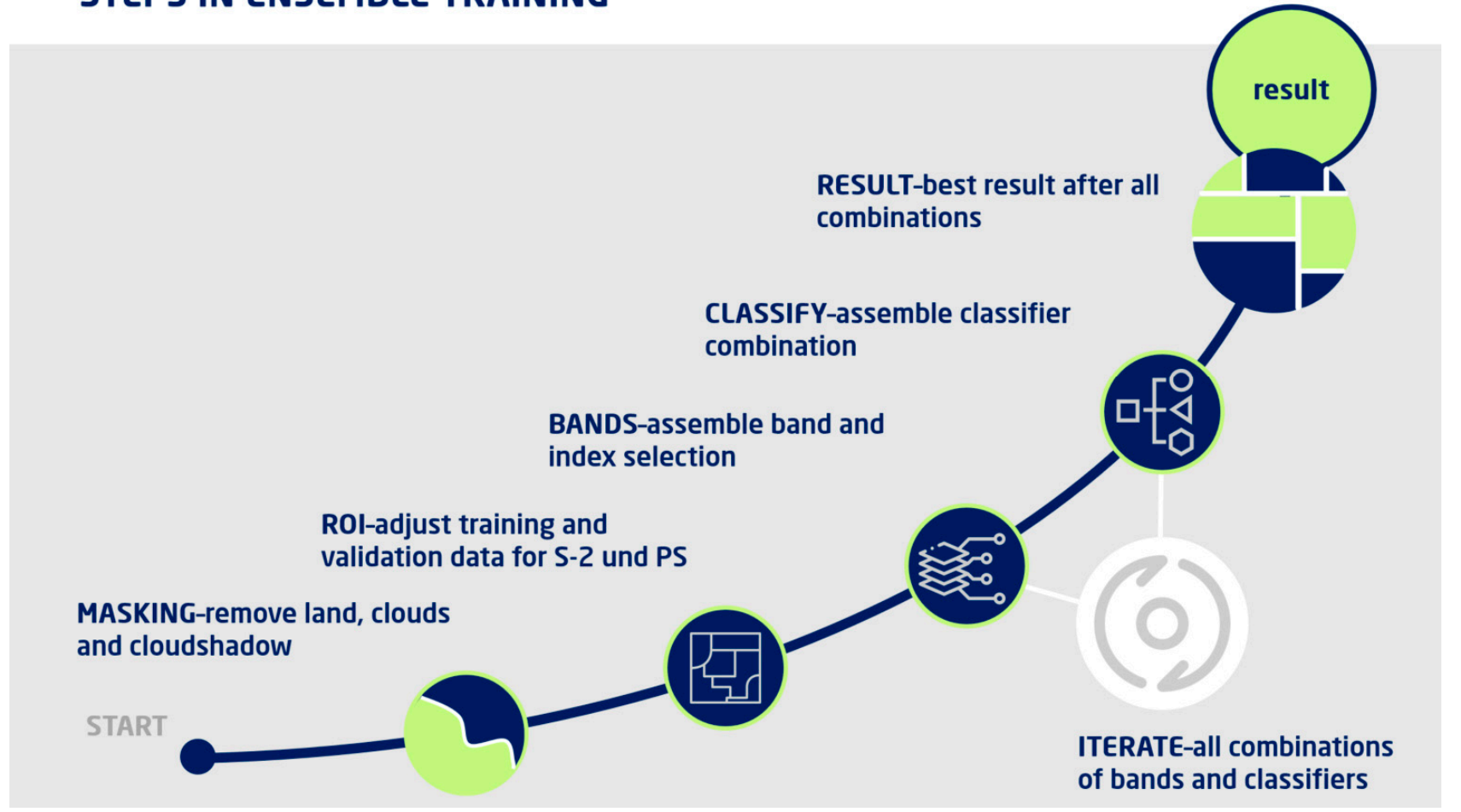

Figure 4. Iterative training of the classifiers for the ensemble with varying band/index combinations as input.

All classifiers in this study are integrated in GEE [39]. Unless explicitly named in the following description of the classifiers, we used the default parameterization of the classifiers in GEE. The methods highlighted with an asterisk are based on the machine learning system Smile v1 [51]:

(1) Random Forest Classifier (RF)*: This ensemble learning decision tree method was run with 100 trees and the number of variables per split (i.e., number of features at each node) was automatically selected as the square root of the number of input variables (bands plus index). 
(2) Cart Classifier (CC)*: A decision tree classifier using only binary trees. CART is characterized by a threshold tuning in every node. Within the decision tree, the attributes are sorted in descending order depending on their information content with respect to the target variable [52,53].

(3) Minimum Distance (MD): This statistic-based classifier classifies pixels to the class with the smallest distance in a (multi) dimensional space. Using the Mahalanobis distance as distance measure which adds a degree of direction sensitivity via the covariance matrix to the method [54].

(4) Support Vector Machine classifier (SVM): This non-parametric statistical learning technique separates classes with a hyperplane by maximizing the distance of the boundaries $[55,56]$. The radial basis function was used as kernel for the SVM.

(5) Naïve Bayes (NB)*: A simple probabilistic classification approach assuming independence between input features. This classifier is characterized by often higher bias but good variance [53,57].

(6) Stochastic Gradient Boosting (SGB)*: This decision tree-based method uses bagging and boosting to improve the quality of fit to each base learner $[58,59]$. The number of trees was set to 100 as an optimal balance between computation time and classification accuracy. A learning rate of $<0.1$ yields improvements to the generalization ability of the model. We found that a learning rate of 0.005 was optimal to achieve a relatively low root mean square error (RMSE). This finding supports the statement of Godinho et al. [60], who suggested this value for tree canopy cover percentage estimation with S-2A. To prevent from over-fitting, the subsampling rate was set to 0.6.

The source code for the shoreline masking and the classification ensembles are available as supplementary material to this study (Code S1).

\subsection{Training and Validation of the Classifiers}

To derive generalizable results from a classification, it is necessary to use independent sets of training and validation data. We gathered field data along approximately $20 \mathrm{~km}$ of shoreline focusing on smaller sections. During the field mappings, we recorded both, the outlines of representative structures and the species compositions of beach cast assemblages using the results to generate training and validation data. Campbell [61] suggests to ensure a total of at least 100 training pixels per class plus additional pixels for the validation. Compared to the spatial resolution of S-2 data the mapped plots were too small to generate the suggested number of training and independent validation data. In total, we mapped $10,678 \mathrm{~m}^{2}$ of reference data during the field campaigns. Transferring these areas to the reference systems of PS and S-2, the total number of pixels covered for all classes is 1186 for the former and 106 for the latter. To increase the number of training and validation pixels, we therefore analyzed the mapped areas in the PS data and used the spectral signatures and the shape of the patterns in the reference plots to identify additional training and validation areas. Without a sufficiently high number of training and validation pixels, spectrally similar surfaces may be included in the classification and therefore negatively affect the classification results. To generate training and validation data for S-2, we created one class of field data which included all species but covered a larger area. Furthermore, the ASM left some pixels with dune vegetation unmasked. To prevent misclassifications, we also added a dune vegetation class. In order to distinguish beach cast and drifting algae from surrounding cover types, we altogether selected seven classes:

(1) Seagrass: This class includes sessile seagrass occurrences at the seafloor. Most of these patches are located below $1 \mathrm{~m}$ water depth and were not mapped during the field campaigns. Therefore, this class was primarily trained by incorporating orthophotos from Google and S-2 false color images, as the location and extend of these patches change slowly.

(2) Water covered sand: The sand covered underwater areas were not directly mapped; however, it appears from the vegetation mappings that unmapped areas mostly represent sand-dominated areas without vegetation. When setting the training areas, 
we included true and false color imagery, as well as reflectance spectra from PS and S-2.

(3) Dune vegetation: The sessile dune vegetation is particularly important as a standalone class, since in the absence of this class these areas would be falsely classified as beach cast. Training and validation data for this class could be extracted by visually inspecting PS CIR imagery in combination with orthophotos.

(4) Deep water: Training and validation data for this class could be obtained by including bathymetry maps (JRC Global Surface Water Mapping Layers, v1.2) and using only water pixels deeper than $25 \mathrm{~m}$ for the training of this class.

(5) Beach sand: This class includes fine sandy beach without the influence of vegetation. Like with the water covered sand class, the training and validation data of this class resulted from the areas between the mapped terrestrial polygons with beach cast.

(6) Beach cast: This class combines all types of beach cast. We did not consider age, degree of decomposition and species composition while creating the training-and validation data. Specifically for this class, the reference patches mapped during the field campaign did not capture enough pixels to ensure a successful training of the classifiers. Therefore, we performed a CIR analysis of the PS data based on the field mapping to generate additional training data.

(7) Drifting vegetation: In this class we recorded all types of drifting macroalgae, which may also include smaller fractions of detached seagrass. For the creation of the training data, we used the results from the field mapping. We analyzed the spectra within the mapped areas and added similar pixels to the selection using the PS CIR images.

Considering the spatial resolution of the two sensors, 2588 pixels were available for the classifications of the S-2 scene and 10,376 pixels for the classification of PS data. For the least represented class (beach cast) there were 74 pixels for S-2 (below Campbell's suggestion) and 230 pixels for PS. During the processing of the data, these pixels were randomly split $50 / 50$ into training and validation data.

For the validation of the classification results, we use the overall accuracy (OA) and $F 1$ score as quality measures [62]. To represent the two particularly relevant classes in a combined measure of quality, we included a combined F1 score (CF1) in the analysis. This score is calculated from the $F 1$ score of beach cast plus the $F 1$ score of drifting vegetation divided by 2 (Equation (1)). Due to the high correlation between the OA and the kappa coefficient, we excluded Cohen's kappa from our analysis [63].

$$
C F 1=\frac{F 1 \text { score }_{\text {drifting vegetation }}+F 1 \text { score }_{\text {beach cast }}}{2}
$$

\section{Results and Discussion}

\subsection{Advanced Shoreline Masking}

The processing chain for ASM shows a very high accuracy to separate the shoreline from the terrestrial areas. The sandy beach together with water covered pixels remain preserved for further analysis during this process. Only a few land pixels $(2.03 \%)$ are incorrectly included (Figure 5), which all are anthropogenic structures with high reflection signals, such as campers at campgrounds, asphalt road intersections, flat roofs of industrial complexes, or rooftop solar arrays. Apart from these erroneously unmasked pixels, the ASM results accurately represent the shoreline. ASM captures only the sandy beach, small stripes of the vegetated dune and the coastal waters while masking the grassland areas behind the dike as well as the asphalt roads on the lee side of the dike. The resolution of $10 \mathrm{~m}$ proved to be suitable for the study area-even small sand-covered passages in the dunes remain unmasked (Figure 5). Along the entire shoreline, all pixels are correctly assigned to the sandy beach. Therefore, the algorithm captured the shape of the shoreline with high accuracy, which can be mainly attributed to the HPF-sharpening of the data. Including the spectral information of band 11 instead of band 8 reduced the amount of falsely unmasked pixels for about $4.08 \%$, although band 11 actually has a lower spatial 
resolution. While ASM provided a very good separation of terrestrial areas, especially close to the shoreline, some water bodies (lakes, rivers) and anthropogenic structures in the hinterland remain unmasked. Therefore, in addition to the procedure described in the methods in Section 2.4, we had to add an additional processing step. We could remove these areas by adding an official shapefile with the terrestrial borders of the country and buffered the outlines $200 \mathrm{~m}$ towards the hinterland. With the resulting polygon of the terrestrial land area, we could mask out all inland pixels that were not covered by ASM. This processing chain enabled to extract the shoreline. To date, published methods for detecting the shoreline from remote sensing data are based on the definition that the shoreline coincides with the physical interface of coastal land and water surface [64-66]. Current processors do not take into account the often dry beach area, which must be preserved for the study of beach cast and publications in this field still remain limited [24]. By using a five-year time series of S-2 data along with spectral indices, we were able to apply a threshold based index approach to automatically detect the shoreline in a way that preserves the entire sandy beach till the subsequent dike. This includes all potential areas of beach cast accumulation.

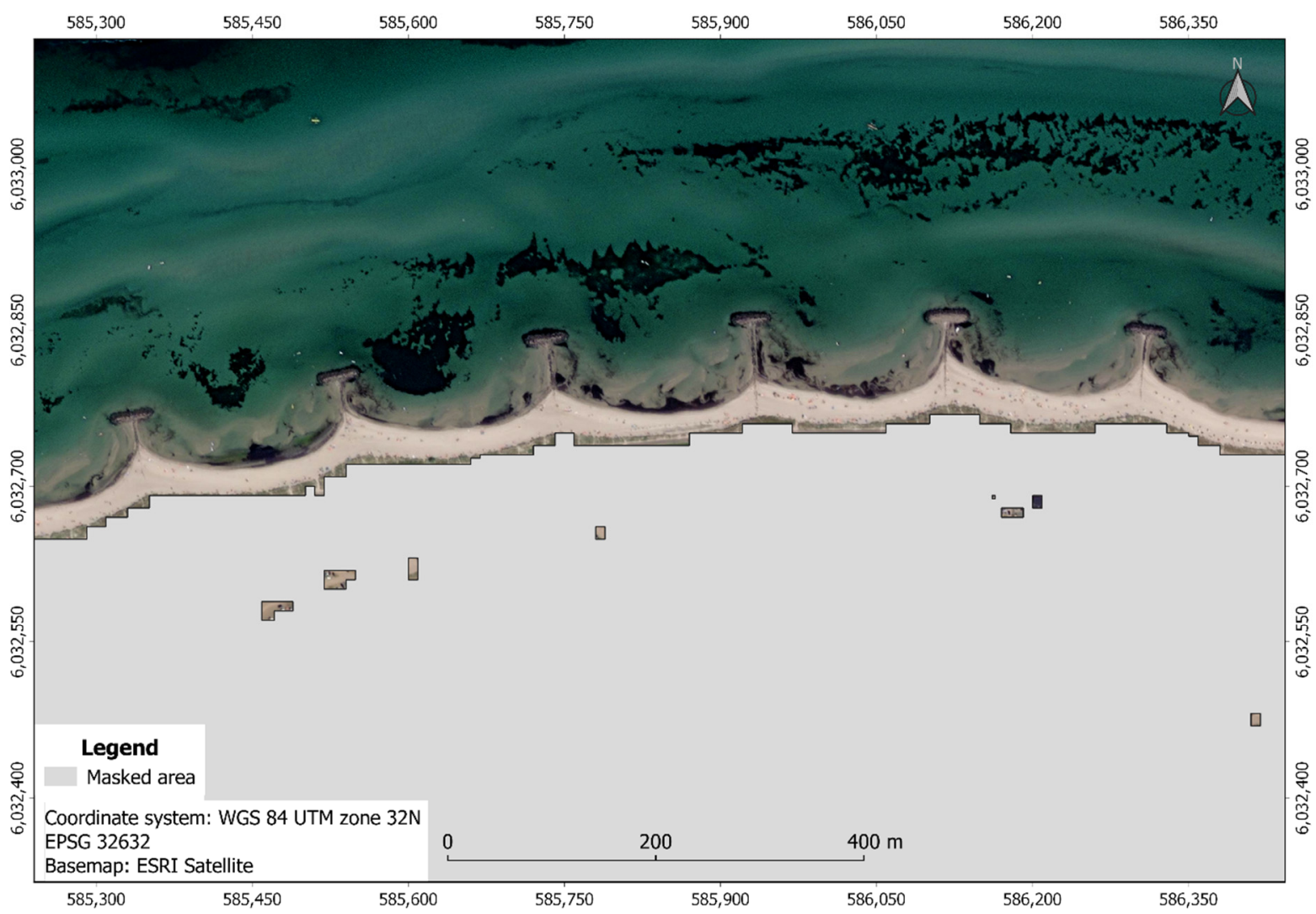

Figure 5. Result of the coastline extraction (example). Grey areas are masked pixels by the ASM approach.

\subsection{Training and Validation}

We used the field mapping results to generate the training and validation data. The procedure to enlarge the number of training data described in the methods is time consuming, prone to errors and was not always successful to generate the targeted minimum of 100 pixels per class for S-2. However, the classification results later showed a realistic spatial distribution of the target habitats. Furthermore, we considered the time interval between the field mapping and the satellite image acquisition to be problematic for the training of small-scale, dynamic habitats. Contrary to this assumption, we could clearly identify the mapped habitats in the remote sensing data based on their shape and reflectance spectra. Therefore, this study showed that even an interval of about one week between the field 
mapping and the satellite acquisition is sufficient for a high classification accuracy. The calm weather conditions during that period have led to stable patterns of beach cast and drifting vegetation.

\subsection{Selection of Thematic Classes}

The groynes in the study area are densely overgrown with stationary Fucales, which was falsely classified as drifting vegetation. An established method to avoid this misclassification is to include a separate (Fucus) class, which we did for several classifications. Different than expected, including the Fucus class significantly reduced classification accuracy. We could identify two reasons for the misclassifications: (1) for both S-2 and PS, the spectral signatures of floating and stationary Fucales were too similar; (2) the two classes were often located close to each other, mixed or showed a smooth transition. Therefore, we removed the class Fucales in our final classifications and accepted a slight overestimation of the drifting vegetation class in the final product. A distinction between sessile Fucus and drifting vegetation is currently not possible with the approach presented here.

\subsection{Band Selection}

For the identification of the most suitable band/index combination, we iteratively combined all classifiers, bands and indices to select the most suitable band combination for the detection of beach cast and drifting vegetation. Because we used all available data in this processing step (no split between training and validating), the accuracy measures shown in Tables 1 and 2 slightly differ from the following section.

Table 1. Classification accuracies (overall accuracy, F1 scores, Combined F1 score) for the six classifiers with the band combination 'B1','B2','B3','B4','B8' for S-2 (green = higher than Table 2, yellow = equal to Table 2, red = lower than Table 2).

\begin{tabular}{ccccccc}
\hline Accuracy Measure & RF & CC & MD & SVM & NB & SGB \\
\hline Overall accuracy & 0.97 & 0.96 & 0.80 & 0.91 & 0.86 & 0.96 \\
F1 score beach cast & 0.83 & 0.78 & 0.54 & 0.70 & 0.51 & 0.68 \\
F1 score drifting vegetation & 0.84 & 0.83 & 0.53 & 0.60 & 0.47 & 0.77 \\
Combined F1 score & 0.84 & 0.80 & 0.54 & 0.65 & 0.49 & 0.73 \\
\hline
\end{tabular}

Table 2. Classification accuracies (overall accuracy, F1 scores, Combined F1 score) for the six classifiers with the band/index combination 'B4','B8','B11','FAI','NDVI' for S-2 (green = higher than Table 1, yellow $=$ equal to Table 2 , red $=$ lower than Table 1 ).

\begin{tabular}{ccccccc}
\hline Accuracy Measure & RF & CC & MD & SVM & NB & SGB \\
\hline Overall accuracy & 0.96 & 0.94 & 0.71 & 0.90 & 0.95 & 0.95 \\
F1 score beach cast & 0.72 & 0.71 & 0.41 & 0.70 & 0.39 & 0.63 \\
F1 score drifting vegetation & 0.81 & 0.70 & 0.18 & 0.60 & 0.05 & 0.78 \\
Combined F1 score & 0.76 & 0.71 & 0.30 & 0.65 & 0.22 & 0.71 \\
\hline
\end{tabular}

The analysis showed, that for given band combinations, all classifiers showed similar behavior with either increasing or decreasing accuracies. As an example, Tables 1 and 2 show the comparison of the results for two band/index combinations for S-2. A green color indicates that the classification accuracy is higher in one table compared to the other. A yellow colorization shows that the values between the two tables are the same, and a red colorization indicates a lower value in the direct comparison.

We also noticed that in general the classifiers performed very well for the additional classes (deep water, water covered sand, dune vegetation, seagrass). Therefore, our accuracy assessments achieved high overall accuracies, even though our target classes rarely reached high F1 scores. As a consequence, we had to pay special attention to the classspecific quality measures. Tables 1 and 2 show, that only the RF classification and the CC 
achieved F1 scores above 0.8 for beach cast and drifting vegetation. This indicates, that only considering band and index combinations is not sufficient to achieve classification accuracies comparable to current studies of aquatic vegetation. Sun et al., 2021 achieved F1-scores above 0.9 for the detection of Ulva prolifera and Sargassum from Landsat 8 OLI imagery [66]. Additionally, Zhongfeng et al., 2018 reported F1-scores above 0.9 for the detection of macroalgae blooms using machine learning with Multi-Layer Perceptron [67]. It is therefore necessary to also evaluate the ensemble of classifiers in order to improve the accuracies of the target classes (Section 3.5). The most suitable band combinations were B1, B2, B3, B4 and B8 for S-2 and all bands of PS. The classification results presented in the following section are based on these band combinations.

\subsection{Classification Results}

The classification results of S-2 and PS differed significantly. This was less evident in the accuracy measures but in the spatial distribution of classes in the final product, i.e., the visual appearance. We determined the best single classifier and ensemble for each sensor based on the overall accuracy and the CF1 Score. For S-2, the CC provided the best results, and the combination of RF, CC, SVM, NB, and SGB formed the best ensemble. The CC achieved an OA of 0.97 and a CF1 score of 0.86 . The lowest single classifier accuracy was achieved by MD. The ensemble was slightly better with an OA of 0.98 and a CF1 score of 0.86 . For PS, the RF classification achieved the best result as a standalone classifier, while the same ensemble as identified for S-2 performed best. The RF achieved accuracy measures of $\mathrm{OA}=0.96$ and CF1 score of 0.94 and the ensemble achieved an OA of 0.95 and a CF1 score of 0.95 (Table 3).

Table 3. Comparison of the best classification results for each sensor/classifier combination. $\mathrm{OA}=$ overall accuracy, $\mathrm{CF} 1=$ combined $\mathrm{F} 1$ score of drifting vegetation and beach cast.

\begin{tabular}{ccccc}
\hline $\begin{array}{c}\text { Accuracy } \\
\text { Measure }\end{array}$ & $\begin{array}{c}\text { S-2 } \\
\text { Cart Classifier }\end{array}$ & $\begin{array}{c}\text { S-2 } \\
\text { Ensemble }\end{array}$ & $\begin{array}{c}\text { PS } \\
\text { Random Forest }\end{array}$ & $\begin{array}{c}\text { PS } \\
\text { Ensemble }\end{array}$ \\
\hline OA & 0.97 & 0.98 & 0.96 & 0.95 \\
CF1 & 0.86 & 0.86 & 0.94 & 0.95 \\
\hline
\end{tabular}

Despite the very high accuracy measures for S-2, it has to be noted that PS performs better for capturing the spatial distribution of beach cast (Figure 6). In general, PS seems to be high suitable for the detection of beach cast; only small patches of dune vegetation were falsely assigned to this class. This can be mainly attributed to the higher spatial resolution of PS and a band setting which is sufficient to discriminate the highly reflective beach sand and the active vegetation signal from the beach cast.

In the S-2 results, the beach cast areas are often single pixels or small clusters/stripes of pixels. The spatial patterns are often difficult to recognize, and the results resemble misclassified pixels, which led to a kind of salt and pepper effect. This is consistent with results of the field mapping, where beach cast often forms narrow stripes with sizes below the spatial resolution of S-2. In a S-2 pixel, the beach cast accumulations must therefore have a strong reflectance signal and a high contrast to the surrounding sand to be classified as such.

The PS classifications capture the spatial distribution of beach cast much better than S2. Since we used the same training regions for both sensors, the number of pixels available for the classification is also of major importance. For PS, the number of training and validation pixels always were sufficiently high to meet the requirements (100 pixels, see also Section 2.6 Training and Validation). For S-2, however, it was not always possible to obtain sufficient training and validation pixels, especially for the target classes. Nevertheless, the field data still in general allowed for very good classification results for S-2; although classification accuracies were highly variable. This is due to the methodological design of our classification, as we randomly split the data for training and validation. Due to the small amount of reference data, changing their share has a strong impact on the results. 


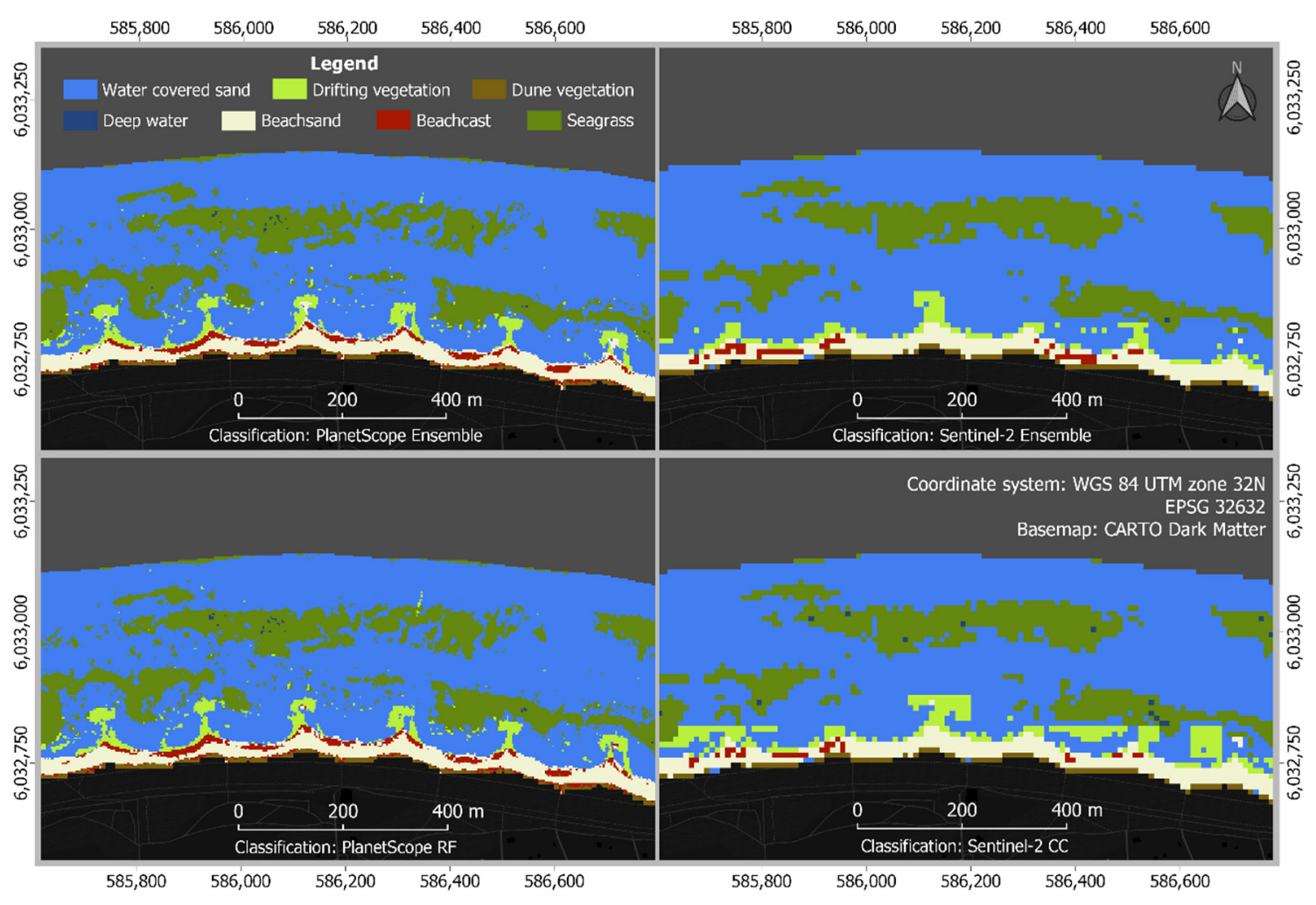

Figure 6. Comparison of the four best classification results for PS and S-2.

The second target class, drifting vegetation, could also be detected with high accuracy (F1 scores $\geq 0.87$ ), but not as good as beach cast. All classifiers overestimate accumulations of drifting vegetation, especially for PS data. As expected, stationary Fucales growing firmly on groynes are incorrectly identified as drifting vegetation (Figure 7). Patches of Fucus and drifting vegetation also partly overlapped, which can be explained by the spectral similarity between Fucus and beach cast. While the separation of Fucus was insufficient, we could successfully separate other structures in the water such as drifting vegetation, seagrass deposits and sandy bottom substrate. Compared to PS, S-2 showed slightly better results in deeper water, which can be attributed to its better Signal to Noise Ratio (SNR) [68]. The single classifiers as well as the ensembles applied in this study showed, however, that they are suitable for shallow water areas. In the deep-water areas, the results show a large number of falsely identified seagrass and deep-water pixels. Our method is not suitable to detect vegetation in optically deep water. We therefore excluded the deep-water areas from analysis.

In addition to the accuracy measures and the visual inspection of the spatial patterns, counting the pixels of each class allows us to assess their spatial coverage and therefore to compare the results of the two sensors. For that, we compared the area allocated to each class. Table 4 shows, that the area covered by drifting vegetation and beach cast is rather similar for PS and S-2 using the different classifiers. The results of the other ensembles or single classifiers confirmed this observation. For S-2, the beach cast area is about $30 \%$ smaller than for PS with a standard deviation between all results of 1.22 ha at an arithmetic mean of 5.95. The calculated area of drifting vegetation shows a lower variance between the ensembles and the standalone classifiers. At an arithmetic mean of $23.57 \mathrm{ha}$, the standard deviation of 2.98 ha corresponds to a variation of $12.65 \%$ around the mean. The S-2 ensemble is an outlier and differs by about $22 \%$ from the arithmetic mean. So, when only considering the area covered by a class, both sensors are equally well suited for detecting drifting vegetation. The beach cast coverages were also comparable. However, the visual evaluation showed that PS can outline the spatial patterns of the beach cast more comprehensively but tends to falsely attribute dune vegetation to beach cast. The 
high spatial resolution of PS data has been described as promising for mapping seagrasses in previous studies but was not tested for beach cast yet [19]. In shallow optical waters, the low SNR and the few spectral bands were limiting factors which, however, plays a minor role on dry sandy beaches [19]. The results of the classification clearly showed that PS is particularly good at capturing the pattern of the often small scale stripes of beach cast. Some of the stripes had a width of only one PS pixel, which corresponds to a maximum width of $3 \mathrm{~m}$. Considering this, we assume that the results achieved with the two sensors are comparable with S-2 having a small advantage in optically shallow waters and PS having a small advantage on dry sandy beaches.

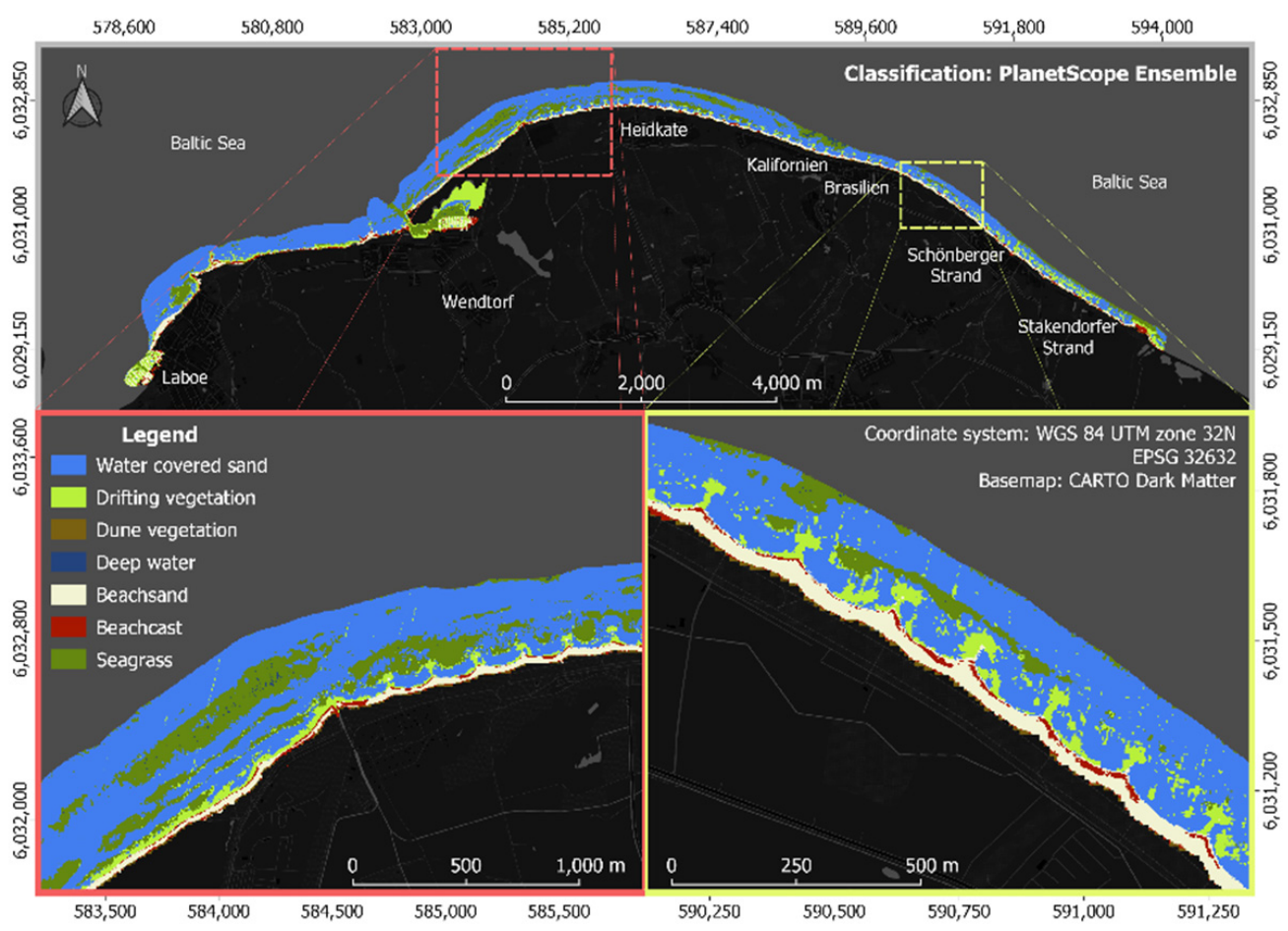

Figure 7. Results of the best classification ensemble run (RF, CC, SVM, NB, SGB) for PS.

Table 4. Mapped area of beach cast and drifting vegetation with the four best classification/ensemble results.

\begin{tabular}{ccc}
\hline Classification/Ensemble & Beach Cast Area [ha] & Drifting Vegetation Area [ha] \\
\hline Sentinel-2 CC & 4.96 & 26.04 \\
Sentinel-2 Ensemble & 4.55 & 18.49 \\
PlanetScope RF & 7.45 & 25.24 \\
PlanetScope Ensemble & 6.83 & 24.50 \\
\hline
\end{tabular}

In water remote sensing, clouds, cloud shadows and haze may influence the results. Affected pixels are often misclassified as aquatic vegetation [69]. Using S-2, we could observe this influence in our study where shallow water areas with sandy bottom were misclassified as either seagrass or drifting vegetation. In these areas, Sen2Cor was unable to correct for a fine haze over the water surface at the coasts of Brasilien and Kalifornien which caused misclassifications. The results show that correcting the influence of clouds and cloud shadows remains a key task in remote sensing of water bodies.

\section{Conclusions}

This study demonstrated the applicability of supervised classifier ensembles to map floating vegetation and beach cast with S-2 and PS data at the German Baltic coast. To extract the shoreline in the satellite data, we developed a new masking method (SHS) based 
on a time series of S-2 data. The shoreline masking achieved a very high accuracy (98\%) and showed, that the use of time series is a promising approach, which can also be applied to other sensors. The advantage of the SHS approach is that it determines an average reflectance for every pixel and therefore removes artifacts from the data. Phenomena such as cloud shadows or haze are compensated and changes in water level or coastline are adjusted to an average value. This prevents false masking due to atmospheric or tidal artefacts and delivers a higher accuracy of the estimated shoreline. By maintaining the high spatial resolution of $10 \mathrm{~m} \times 10 \mathrm{~m}$ and using the reflectance in band 11 (NIR), we could extract the shoreline including the sandy beach together with all water covered areas.

Generally, S-2 and PS are suitable for the detection of beach cast and drifting vegetation. The most suitable combination of bands is nearly identical for both sensors. For PS and S-2 the spectral information of the bands in the Visible and Near Infrared delivered the best results. The best single classifier result for S-2 is provided by CC with an OA of 0.97 and a CF1 score of 0.86. RF, CC, SVM, NB, and SGB together formed the best ensemble for S-2 with an OA of 0.98 and a CF1 score of 0.86 . The best single classifier result for PS is provided by RF with an OA 0.96 and a CF1 score of 0.94 . The same ensemble as identified for S-2 performed best for PS with an OA of 0.95 and a CF1 score of 0.95 . The average detected coverage (arithmetic mean) of beach cast is 5.95 ha with a standard deviation of 1.22 ha and therefore differed approx. 21\% between the classifications. The mapped coverages of drifting vegetation showed smaller variations of only about $13 \%$-the arithmetic mean was 23.57 ha with a standard deviation of 2.98 ha. However, we found that the differences become particularly evident in the spatial distribution of the two classes. Due to its better spatial resolution, PS can map the distribution and shape of beach cast more accurately. The advantages of S-2 are evident in the detection of drifting vegetation. Due to the better SNR, S-2 can better separate drifting vegetation, sandy substrate and submerged seagrass. However, we were not able to monitor the species contribution of drifting vegetation and beach cast, most probably due to the limitations of multi-spectral sensors. To enable a permanent monitoring, the next step is, that the approach will be transferred to time series data.

Supplementary Materials: The following supporting information can be downloaded at: https: / / www.mdpi.com/article/10.3390/geosciences12010015/s1, Code S1: Script for the Google Earth Engine for shoreline masking and classification ensembles.

Author Contributions: Conceptualization, F.U. and N.O.; methodology, F.U.; software, F.U.; validation, F.U. and T.R.G.; formal analysis, F.U.; writing—original draft preparation, F.U.; writing-review and editing, N.O. and F.U.; visualization, F.U.; supervision, N.O. All authors have read and agreed to the published version of the manuscript.

Funding: This research received no external funding.

Institutional Review Board Statement: Not applicable.

Informed Consent Statement: Not applicable.

Data Availability Statement: The Sentinel-2 data used in this study are freely available through the GEE.

Conflicts of Interest: The authors declare no conflict of interest. 


\section{References}

1. Vousdoukas, M.I.; Ranasinghe, R.; Mentaschi, L.; Plomaritis, T.A.; Athanasiou, P.; Luijendijk, A.; Feyen, L. Sandy coastlines under threat of erosion. Nat. Clim. Chang. 2020, 10, 260-263. [CrossRef]

2. Defeo, O.; McLachlan, A.; Schoeman, D.S.; Schlacher, T.A.; Dugan, J.; Jones, A.; Lastra, M.; Scapini, F. Threats to sandy beach ecosystems: A review. Estuarine, Coastal. Shelf Sci. 2009, 81, 1-12. [CrossRef]

3. McLachlan, A.; Brown, A.C. The Ecology of Sandy Shores, 2nd ed.; Elsevier: Amsterdam, The Netherlands, 2006; ISBN 978-0-12-372569-1.

4. Crawley, K.R.; Hyndes, G.A.; Vanderklift, M.A.; Revill, A.T.; Nichols, P.D. Allochthonous brown algae are the primary food source for consumers in a temperate, coastal environment. Mar. Ecol. Prog. Ser. 2009, 376, 33-44. [CrossRef]

5. Corbí, H.; Riquelme, A.; Megías-Baños, C.; Abellan, A. 3-D Morphological Change Analysis of a Beach with Seagrass Berm Using a Terrestrial Laser Scanner. IJGI 2018, 7, 234. [CrossRef]

6. Malm, T.; Råberg, S.; Fell, S.; Carlsson, P. Effects of beach cast cleaning on beach quality, microbial food web, and littoral macrofaunal biodiversity. Estuarine, Coastal. Shelf Sci. 2004, 60, 339-347. [CrossRef]

7. Alber, M.; Valiela, I. Incorporation of organic aggregates by marine mussels. Mar. Biol. 1994, 121, 259-265. [CrossRef]

8. Hansson, S.; Larsson, U.; Johansson, S. Selective predation by herring and mysids, and zooplankton community structure in a Baltic Sea coastal area. J. Plankton. Res. 1990, 12, 1099-1116. [CrossRef]

9. van der Merwe, D.; McLachlan, A. Significance of free-floating macrophytes in the ecology of a sandy beach surf zone. Mar. Ecol. Prog. Ser. 1987, 38, 53-63. [CrossRef]

10. Lenanton, R.C.; Robertson, A.I.; Hansen, J.A. Nearshore Accumulations of Detached Macrophytes as Nursery Areas for Fish. Mar. Ecol. Prog. Ser. 1982, 9, 51-57. [CrossRef]

11. Orr, K.K.; Wilding, T.A.; Horstmeyer, L.; Weigl, S.; Heymans, J.J. Detached macroalgae: Its importance to inshore sandy beach fauna. Estuarine, Coastal. Shelf Sci. 2014, 150, 125-135. [CrossRef]

12. Suursaar, Ü.; Torn, K.; Martin, G.; Herkül, K.; Kullas, T. Formation and species composition of stormcast beach wrack in the Gulf of Riga, Baltic Sea **The study was supported by the EU Life+project MARMONI 'Innovative approaches for marine biodiversity monitoring and assessment of conservation status of nature values in the Baltic Sea', ESF grant No. 8980, Estonian target financed project SF0180104s08 and Institutional research funding IUT2-20 of the Estonian Research Council. Oceanologia 2014, 56, 673-695. [CrossRef]

13. Olmedo-Masat, O.M.; Raffo, M.P.; Rodríguez-Pérez, D.; Arijón, M.; Sánchez-Carnero, N. How Far Can We Classify Macroalgae Remotely? An Example Using a New Spectral Library of Species from the South West Atlantic (Argentine Patagonia). Remote Sens. 2020, 12, 3870. [CrossRef]

14. Veettil, B.K.; Ward, R.D.; Lima, M.D.A.C.; Stankovic, M.; Hoai, P.N.; Quang, N.X. Opportunities for seagrass research derived from remote sensing: A review of current methods. Ecol. Indic. 2020, 117, 106560. [CrossRef]

15. Karki, S.; Bermejo, R.; Wilkes, R.; Monagail, M.M.; Daly, E.; Healy, M.; Hanafin, J.; McKinstry, A.; Mellander, P.-E.; Fenton, O.; et al. Mapping Spatial Distribution and Biomass of Intertidal Ulva Blooms Using Machine Learning and Earth Observation. Front. Mar. Sci. 2021, 8, 380. [CrossRef]

16. Tamondong, A.M.; Cruz, C.A.; Guihawan, J.; Garcia, M.; Quides, R.R.; Cruz, J.A.; Blanco, A.C. Remote sensing-based estimation of seagrass percent cover and LAI for above ground carbon sequestration mapping. In Proceedings of the Remote Sensing of the Open and Coastal Ocean and Inland Waters. Remote Sensing of the Open and Coastal Ocean and Inland Waters, Honolulu, HI, USA, 26 September 2018; Frouin, R.J., Murakami, H., Eds.; SPIE: Bellingham, DC, USA, 2018; p. 2, ISBN 9781510621312.

17. Murray, N.J.; Keith, D.A.; Bland, L.M.; Ferrari, R.; Lyons, M.B.; Lucas, R.; Pettorelli, N.; Nicholson, E. The role of satellite remote sensing in structured ecosystem risk assessments. Sci. Total Environ. 2018, 619-620, 249-257. [CrossRef] [PubMed]

18. Traganos, D.; Cerra, D.; Reinartz, P. Cubesat-derived detection of seagrasses using planet imagery following unmixing-based denoising: Is small the next big? Int. Arch. Photogramm. Remote Sens. Spat. Inf. Sci. 2017, XLII-1/W1, 283-287. [CrossRef]

19. Wicaksono, P.; Lazuardi, W. Assessment of PlanetScope images for benthic habitat and seagrass species mapping in a complex optically shallow water environment. Int. J. Remote Sens. 2018, 39, 5739-5765. [CrossRef]

20. Hang, N.T.T.; Hoa, N.T.; van Tu, N.; Lam, N.N. Spatial distribution of submerged aquatic vegetation in an Chan coastal waters, Phu Yen province using the PlanetScope satellite image. Vietnam. J. EARTH Sci. 2019, 41, 358-373. [CrossRef]

21. Traganos, D.; Reinartz, P. Mapping Mediterranean seagrasses with Sentinel-2 imagery. Mar. Pollut. Bull. 2018, 134, 197-209. [CrossRef]

22. Fauzan, M.A.; Kumara, I.S.W.; Yogyantoro, R.N.; Suwardana, S.W.; Fadhilah, N.; Nurmalasari, I.; Apriyani, S.; Wicaksono, P. Assessing the Capability of Sentinel-2A Data for Mapping Seagrass Percent Cover in Jerowaru, East Lombok. IJG 2017, 49, 195. [CrossRef]

23. Saini, R.; Ghosh, S.K. Ensemble classifiers in remote sensing: A review. In Proceedings of the 2017 International Conference on Computing, Communication and Automation (ICCCA), IEEE, Greater Noida, India, 5-6 May 2017; pp. 1148-1152.

24. Toure, S.; Diop, O.; Kpalma, K.; Maiga, A. Shoreline Detection using Optical Remote Sensing: A Review. IJGI 2019 , 8, 75. [CrossRef]

25. Dolan, R.; Hayden, B.P.; May, P.; May, S. The reliability of shoreline change measurements from aerial photographs. Shore Beach 1980, 48, 22-29.

26. Boak, E.H.; Turner, I.L. Shoreline Definition and Detection: A Review. J. Coast. Res. 2005, 214, 688-703. [CrossRef] 
27. Qu, J.; Wang, C. A multi-threshold based morphological approach for extracting coastal line feature in remote sensed images. In Proceedings of the Pecora 15/Land Satellite Information IV/ISPRS Commission I/FIEOS 2002 Conference Proceedings, Denver, CO, USA, 10-14 November 2002.

28. Aedla, R.; Dwarakish, G.S.; Reddy, D.V. Automatic Shoreline Detection and Change Detection Analysis of NetravatiGurpurRivermouth Using Histogram Equalization and Adaptive Thresholding Techniques. Aquat. Procedia 2015, 4, 563-570. [CrossRef]

29. Bamdadinejad, M.; Ketabdari, M.J.; Chavooshi, S.M.H. Shoreline Extraction Using Image Processing of Satellite Imageries. J Indian Soc. Remote Sens. 2021, 49, 2365-2375. [CrossRef]

30. Bayram, B.; Janpaule, I.; Oğurlu, M.; Bozkurt, S.; Reis, H.Ç.; Şeker, D.Z. Shoreline Extraction and Change Detection using 1:5000 Scale Orthophoto Maps: A Case Study of Latvia-Riga. Int. J. Environ. Geoinform. 2015, 2, 1-6. [CrossRef]

31. $\mathrm{Hu}, \mathrm{C}$. A novel ocean color index to detect floating algae in the global oceans. Remote Sens. Environ. 2009, 113, 2118-2129. [CrossRef]

32. Gao, B. NDWI-A normalized difference water index for remote sensing of vegetation liquid water from space. Remote Sens. Environ. 1996, 58, 257-266. [CrossRef]

33. Schwarzer, K. Exchange of beach sediment between beaches and bars after a beach nourishment. In Proceedings of the International Meeting "Coastal Protection, International Experiences and Prospect", Nantes, France, 7-11 October 1991; pp. 126-133.

34. Schwarzer, K.; Diesing, M. Sediment Redeposition in Nearshore Areas-Examples from the Baltic Sea. In Proceedings of the Coastal Dynamics'01. Fourth Conference on Coastal Dynamics, Lund, Sweden, 11-15 June 2001; Hanson, H., Larson, M., Eds.; American Society of Civil Engineers: Reston, VA, USA, 2001; pp. 808-817, ISBN 978-0-7844-0566-6.

35. Reese, S.; Markau, H.-J. Risk Handling \& Natural Hazards: New Strategies in Coastal Defense-A Case Study from SchleswigHolstein, Germany. In Proceedings of the Solutions to Coastal Disasters'02. Coastal Disasters Conference 2002, San Diego, CA, USA, 24-27 February 2002; Ewing, L., Wallendorf, L., Eds.; American Society of Civil Engineers: Reston, VA, USA, 2002; pp. 498-510, ISBN 9780784406052.

36. Garmin Ltd. GPSMAP®64 SERIES/GPSMAP 64X SERIES Owner's Manual; Garmin Ltd.: Lenexa, KS, USA, 2013.

37. Drusch, M.; Del Bello, U.; Carlier, S.; Colin, O.; Fernandez, V.; Gascon, F.; Hoersch, B.; Isola, C.; Laberinti, P.; Martimort, P.; et al. Sentinel-2: ESA's Optical High-Resolution Mission for GMES Operational Services. Remote Sens. Environ. 2012, 120, 25-36. [CrossRef]

38. ESA. Sentinel-2 User Handbook: User Guide. Available online: https://sentinels.copernicus.eu/documents/247904/685211/ Sentinel-2_User_Handbook.pdf/8869acdf-fd84-43ec-ae8c-3e80a436a16c?t=1438296087000 (accessed on 12 June 2021).

39. Gorelick, N.; Hancher, M.; Dixon, M.; Ilyushchenko, S.; Thau, D.; Moore, R. Google Earth Engine: Planetary-scale geospatial analysis for everyone. Remote Sens. Environ. 2017, 202, 18-27. [CrossRef]

40. Main-Knorn, M.; Pflug, B.; Louis, J.; Debaecker, V.; Müller-Wilm, U.; Gascon, F. Sen2Cor for Sentinel-2. In Proceedings of the Image and Signal Processing for Remote Sensing XXIII. Image and Signal Processing for Remote Sensing, Warsaw, Poland, 11-14 September 2017; Bruzzone, L., Bovolo, F., Benediktsson, J.A., Eds.; SPIE: Bellingham, DC, USA, 2017; p. 3, ISBN 9781510613188.

41. Kotchenova, S.Y.; Vermote, E.F.; Matarrese, R.; Klemm, F.J. Validation of a vector version of the $6 \mathrm{~S}$ radiative transfer code for atmospheric correction of satellite data. Part I Path Radiance Appl. Opt. 2006, 45, 6762-6774. [CrossRef]

42. Planet Labs Inc. Planet Surface Reflectance Product v2. Available online: https://assets.planet.com/marketing/PDF/Planet_ Surface_Reflectance_Technical_White_Paper.pdf (accessed on 20 September 2021).

43. Planet Labs Inc. PLANET IMAGERY PRODUCT SPECIFICATIONS. Available online: https://assets.planet.com/docs/Planet_ Combined_Imagery_Product_Specs_letter_screen.pdf (accessed on 20 September 2021).

44. Du, Y.; Zhang, Y.; Ling, F.; Wang, Q.; Li, W.; Li, X. Water Bodies' Mapping from Sentinel-2 Imagery with Modified Normalized Difference Water Index at 10-m Spatial Resolution Produced by Sharpening the SWIR Band. Remote Sens. 2016, 8, 354. [CrossRef]

45. Chavez, P.S., Jr.; Sides, S.C.; Anderson, J.A. Comparison of three different methods to merge multiresolution and multispectral data: Landsat TM and SPOT panchromatic. Photogramm. Eng. Remote Sens. 1991, 57, 295-303.

46. Zhou, W.; Li, Z.; Ji, S.; Hua, C.; Fan, W. A New Index Model NDVI-MNDWI for Water Object Extraction in Hybrid Area. In Proceedings of the Geo-Informatics in Resource Management and Sustainable Ecosystem, Ypsilanti, MI, USA, 3-5 October 2014; Bian, F., Xie, Y., Eds.; Springer: Berlin, Germany, 2015; pp. 513-519, ISBN 978-3-662-45736-8.

47. Briem, G.J.; Benediktsson, J.A.; Sveinsson, J.R. Multiple classifiers applied to multisource remote sensing data. IEEE Trans. Geosci. Remote Sens. 2002, 40, 2291-2299. [CrossRef]

48. Pal, M. Random forest classifier for remote sensing classification. Int. J. Remote Sens. 2005, 26, 217-222. [CrossRef]

49. Du, P.; Xia, J.; Zhang, W.; Tan, K.; Liu, Y.; Liu, S. Multiple classifier system for remote sensing image classification: A review. Sensors (Basel) 2012, 12, 4764-4792. [CrossRef]

50. Haifeng, L. Smile-Statistical Machine Intelligence and Learning Engine. 2014. Available online: https://haifengl.github.io. (accessed on 20 September 2021).

51. Breiman, L.; Friedman, J.H.; Olshen, R.A.; Stone, C.J. Classification and Regression Trees; Routledge: London, UK, 2017; ISBN 9781315139470.

52. Shelestov, A.; Lavreniuk, M.; Kussul, N.; Novikov, A.; Skakun, S. Exploring Google Earth Engine Platform for Big Data Processing: Classification of Multi-Temporal Satellite Imagery for Crop Mapping. Front. Earth Sci. 2017, 5, 17. [CrossRef] 
53. Richards, J.A. Remote Sensing Digital Image Analysis: An Introduction, 5th ed.; Springer: Berlin, Germany, 2013; ISBN 978-3-642-30062-2.

54. Kang, J.; Zhang, H.; Yang, H.; Zhang, L. Support Vector Machine Classification of Crop Lands Using Sentinel-2 Imagery. In Proceedings of the 2018 7th International Conference on Agro-Geoinformatics (Agro-Geoinformatics), IEEE, Hangzhou, China, 6-9 August 2018; pp. 1-6, ISBN 978-1-5386-5038-7.

55. Saini, R.; Ghosh, S.K. Crop classification on single date sentinel-2 imagery using random forest and suppor vector machine. Int. Arch. Photogramm. Remote Sens. Spat. Inf. Sci. 2018, XLII-5, 683-688. [CrossRef]

56. Haykin, S.S. Neural Networks and Learning Machines, 3rd ed.; Pearson: New York, NY, USA, 2009; ISBN 978-0-13-147139-9.

57. Friedman, J.H. Greedy function approximation: A gradient boosting machine. Ann. Statist. 2001, 29, 1189-1232. [CrossRef]

58. Friedman, J.H. Stochastic gradient boosting. Comput. Stat. Data Anal. 2002, 38, 367-378. [CrossRef]

59. Godinho, S.; Guiomar, N.; Gil, A. Estimating tree canopy cover percentage in a mediterranean silvopastoral systems using Sentinel-2A imagery and the stochastic gradient boosting algorithm. Int. J. Remote Sens. 2018, 39, 4640-4662. [CrossRef]

60. Campbell, J.B. Introduction to Remote Sensing, 5th ed.; Guilford Press: New York, NY, USA, 2011; ISBN 9781462506750.

61. Maxwell, A.E.; Warner, T.A. Thematic Classification Accuracy Assessment with Inherently Uncertain Boundaries: An Argument for Center-Weighted Accuracy Assessment Metrics. Remote Sens. 2020, 12, 1905. [CrossRef]

62. Pontius, R.G.; Millones, M. Death to Kappa: Birth of quantity disagreement and allocation disagreement for accuracy assessment. Int. J. Remote Sens. 2011, 32, 4407-4429. [CrossRef]

63. Yasir, M.; Sheng, H.; Fan, H.; Nazir, S.; Niang, A.J.; Salauddin, M.; Khan, S. Automatic Coastline Extraction and Changes Analysis Using Remote Sensing and GIS Technology. IEEE Access 2020, 8, 180156-180170. [CrossRef]

64. Gens, R. Remote sensing of coastlines: Detection, extraction and monitoring. Int. J. Remote Sens. 2010, 31, 1819-1836. [CrossRef]

65. Dellepiane, S.; de Laurentiis, R.; Giordano, F. Coastline extraction from SAR images and a method for the evaluation of the coastline precision. Pattern Recognit. Lett. 2004, 25, 1461-1470. [CrossRef]

66. Sun, D.; Chen, Y.; Wang, S.; Zhang, H.; Qiu, Z.; Mao, Z.; He, Y. Using Landsat 8 OLI data to differentiate Sargassum and Ulva prolifera blooms in the South Yellow Sea. Int. J. Appl. Earth Obs. Geoinf. 2021, 98, 102302. [CrossRef]

67. Qiu, Z.; Li, Z.; Bilal, M.; Wang, S.; Sun, D.; Chen, Y. Automatic method to monitor floating macroalgae blooms based on multilayer perceptron: Case study of Yellow Sea using GOCI images. Opt. Express 2018, 26, 26810-26829. [CrossRef] [PubMed]

68. Jorge, D.; Barbosa, C.; Affonso, A.; Lobo, F.; Novo, E. SNR (Signal-To-Noise Ratio) Impact on Water Constituent Retrieval from Simulated Images of Optically Complex Amazon Lakes. Remote Sens. 2017, 9, 644. [CrossRef]

69. Nijland, W.; Reshitnyk, L.; Rubidge, E. Satellite remote sensing of canopy-forming kelp on a complex coastline: A novel procedure using the Landsat image archive. Remote Sens. Environ. 2019, 220, 41-50. [CrossRef] 